This item was submitted to Loughborough's Research Repository by the author.

Items in Figshare are protected by copyright, with all rights reserved, unless otherwise indicated.

\title{
Introduction: political psychology as an interpretive field
}

\section{PLEASE CITE THE PUBLISHED VERSION}

http://www.cambridge.org/tn/academic/subjects/psychology/social-psychology/political-psychology-criticalperspectives?format=PB

\section{PUBLISHER}

(C) Cambridge University Press (CUP)

VERSION

VoR (Version of Record)

LICENCE

CC BY-NC-ND 4.0

\section{REPOSITORY RECORD}

Tileaga, Cristian. 2019. "Introduction: Political Psychology as an Interpretive Field". figshare. https://hdl.handle.net/2134/21594. 
Cambridge University Press

978-1-107-01768-9 - Political Psychology: Critical Perspectives

Cristian Tileagă

Excerpt

More information

\section{Introduction: political psychology as an interpretive field}

\section{Psychology and politics}

The American political scientist Charles E. Merriam described psychology as a 'kindred' science (Merriam, 1924). McGuire (1993) writes about the 'long affair' between psychology and political science underpinned by frequent transformation of topics, procedures and theories. What Merriam and McGuire have in common is that they understand the relationship between psychology and politics as the study of 'political behaviour'. A variety of 'definitions' of this relationship has been suggested. For example, Sears et al. (2003) see the relationship between psychology and politics as the 'application of what is known about human psychology to the study of politics' (p. 3). For others, it is about discerning how 'human cognition and emotion mediate the impact of the environment on political action' (Stein, 2002, p. 108). According to Lavine (2010), the relationship is 'defined by a bidirectional influence: just as the psyche influences political orientation, the polity leaves its mark on who we are' (p. xx, emphasis in original).

This book does not attempt to offer yet another definition. Instead, it tries to qualify the relationship between psychology and politics by proposing alternative approaches, different conceptual tools and a different vision of human psychology and political behaviour with roots in epistemological, theoretical and methodological presuppositions arising from the discursive (Billig, 1987; Harré and Gillett, 1994; Middleton and Edwards, 1990), narrative (Bruner, 1986; Polkinghorne, 1988) and sociocultural (Middleton and Brown, 2005; Valsiner, 2007; Wertsch, 2002) turns in psychology, the human and the social sciences, giving rise to what can be broadly termed an interpretive political psychology. An interpretive political psychology suggests that political psychologists can attain a deep level of understanding of political behaviour by researching different social and political orders - discursive, cultural and semiotic - in their own terms. When political psychologists research attitudes, racism, public opinion, political ideology, and so on, 
Cambridge University Press

978-1-107-01768-9 - Political Psychology: Critical Perspectives

Cristian Tileagă

Excerpt

More information

they are, arguably, describing universalistic and particularistic presuppositions of modern culture. An interpretive political psychology likens the work of the political psychologist to that of the anthropologist who uncovers the various meaning-making layers through which society is organised and reproduces itself (Moscovici, 1972).

The book describes a style of doing political psychology in Europe that has developed out of dialogue with, as well as critique, of North American approaches. It has been argued that political psychology can be described as a 'problem-centred field', whose concerns arise from 'those social problems and puzzles that emerge throughout history and in specific locales' (Nesbitt-Larking and Kinnvall, 2012, p. 46). European social and political psychologists have a long tradition of exploring distinctively European political and social psychological issues such as fascism and bigotry, ideology and nationalism, social and political identity, values and political attitudes, collective action, mass and elite constructions and understandings of politics. To these one can add more recent concerns with the relationship between national and European identity, 'New Europe', political memory and identity, ethnic minority construction and ethnic identification, understanding social and political change in Western and Eastern Europe. It is hoped that the book will make a timely contribution and advance political psychology by putting European research perspectives firmly on its intellectual and empirical agenda.

There are many books on political psychology, but very few devote much attention to European approaches. For instance, the latest fourvolume set on Political Psychology, edited by Howard Lavine (2010), makes only scant reference to European political concerns or European social psychological contributions. This conspicuous absence cannot be disregarded because it reproduces a skewed vision of what political psychology is and how it is actually practised around the world. This book is an attempt to redress the balance by fostering debate around relatively underrepresented perspectives in political psychology that can provide a renewed foundation or check for contemporary analyses of political behaviour. The aim is not to further divisions, but encourage perspectives particularly suited to the declared task of developing a genuinely international dialogue of traditions of research in political psychology around the world (Haste, 2012).

\section{Interpretive political psychology}

The inclusion of an interpretive dimension in political psychology has three major implications. First, it can expand political psychology's 
Cambridge University Press

978-1-107-01768-9 - Political Psychology: Critical Perspectives

Cristian Tileagă

Excerpt

More information

Interpretive political psychology

traditional focus on political behaviour, narrowly understood in an individualistic theoretical and methodological framework. Much of the theoretical and empirical content of contemporary political psychology is driven by the search for explanations of real-life events in the 'real' political world and scene. These explanations have as a basis the testing of abstract academic theories, the prediction and modelling of political behaviour rather than real-life events and practices, interpreted in their own terms, with academic theory or models merely as an appui. As Marková has recently argued, the discipline of social psychology has historically nurtured and enforced the use of 'methods of proof', opposed to 'methods of discovery' (2012, p. 113). This has led to social and political psychologists not being able to address directly in their work the tension between the requirements of scientific knowledge and the less easily definable and discernible features of political behaviour they are researching. As Serge Moscovici has aptly noted, the relationship between psychology and politics is necessary, functional and yet sometimes unpredictable and not at all obvious (Moscovici, 1989).

Second, it can foster a debate about the meaning of 'scientific knowledge' that crosses beyond the experimental or survey canon that dominates contemporary political psychology. As Sandra Jovchelovitch argues, 'within psychology... there is a strong tendency to consider lay knowledge and everyday understandings as obstacles, noise and errors to be removed: the superstitions, mythologies and false beliefs they carry should be replaced with the truth of expert or scientific knowledge' (2008, p. 437). It should be the task of political psychology to discover principles; not only universal, but also contingent, relative principles underlying the interpenetration of discursive, cultural and semiotic orders. One must broaden the sweep of social scientific enquiry, away from the nature of the thinking individual and belief systems to massmediated communication, social interaction, social practices and lay sources of knowledge. It is perhaps erroneous to think that simply using 'adequate methods is equivalent to scientific investigation' (Moscovici, 1972, p. 21). Political psychologists need to respond to explicit challenges of studying social and political behaviour and challenges set by their colleagues in other disciplines. Political psychology has started the dialogue with biology, genetics, neurosciences; yet, at the same time, it neglects its dialogue with linguistics, critical psychology, sociology, media studies, or philosophy. In order to enrich the depth and breadth of its conclusions and impact in the 'real' world it needs to draw upon some of their assumptions, questions and methods. As a genuinely interdisciplinary project political psychology should be able to provide 
Cambridge University Press

978-1-107-01768-9 - Political Psychology: Critical Perspectives

Cristian Tileagă

Excerpt

More information

the intellectual space in which concepts and theoretical traditions from different fields can cohabit.

Third, it can lead to a reconsideration of the image of the person and society implicit in contemporary scientific approaches and a re-examination of political psychology's conception of the relation between human nature, language and culture. As the chapters of this book show, public opinion, democratisation, personality, prejudice, collective memory, and many other notions with origins in social and political theory are concepts connected in myriad ways to concerns of culture, language and community. The increasingly fine technologies of polling, experimentation and neuro-imaging construct individuals that "come to "fit" the demands of the research; they become, so to speak, persons that are by nature "researchable" from that perspective' (Osborne and Rose, 1999, p. 392). We tend to confine to strict experimental situations and cognitive modelling what is already diffused (in some form or other) in culture (cf. Moscovici, 1972). As Moscovici suggested, it is society's 'social theory' that we need to be able to discern, to describe, to analyse; social and political psychology is not practised in a 'social vacuum' (Tajfel, 1972).

Political psychologists seem to stop short of examining social and political life in depth and very rarely concern themselves with what Allport called 'the concrete person'. Political psychological analyses should not only be derived from general laws and psychological concepts but rather from lives (as actually lived) and social practices (as actually performed). One ought to start not only with the question of how reality is intelligible to us, as researchers, but how reality is intelligible to social actors who experience it as such. As political psychologists we should consider seriously idiographic aspects of social existence, and treat people and politics as products of social activities and social practices.

The relationship between psychology and politics stands in need of explanation; it does not explain anything in itself. What we make of it is constituted, and limited, by our techniques of measuring it, our narratives, our discourses, our representations, our identities, our collective memories. Following Moscovici, this book argues that political psychology has remained for too long the prisoner of a 'pragmatic culture' that evades the contingent, relative, particularistic aspects of social and political experience.

There is a further point to be made, and this pertains to European political psychology. Only by becoming an interpretive discipline can European political psychology develop itself as a worthwhile enterprise. The themes of its research and the contents of its theories do 
Cambridge University Press

978-1-107-01768-9 - Political Psychology: Critical Perspectives

Cristian Tileagă

Excerpt

More information

not need to be borrowed from across the Atlantic; they must reflect the issues of its own social and political organisation. In 1972, Moscovici identified the 'advantage' of American social psychology as being not necessarily one of methodological or theoretical advance but more an issue of taking 'for its theme of research and for the contents of its theories the issues of its own society ... and making them an object of scientific enquiry' (1972, p. 19, emphasis in original; see also Moscovici and Marková, 2006 for a history of the development of social psychology in Europe).

Contemporary European political psychology must heed Moscovici's message; it must turn towards its own social and political realities, devise its own axioms, hypotheses and questions, from which it can derive its own 'scientific consequences' (Moscovici, 1972, p. 19).

\section{Political behaviour as social practice}

It is conventionally assumed that the task of the political psychologist is to account for the variety of manifestations and complexity of political behaviour. The political psychologist is generally interested in problems and solutions to these problems that are valid in their own right for everyone, at any time and at any place. A consequence of this is that political behaviour is mostly conceived of as the result of universal, habitual and automatic processes rather than as a product of human social practices. Another consequence of this is that actual behaviour is given less and less attention (Baumeister et al., 2007; Potter, 2012).

Political psychologists devise more and more complex technical vocabularies used to describe political behaviour. The contemporary political psychology of political behaviour is founded on the epistemological structure of 'justified belief' against a reality 'out there' which expects description and explanation. The route to knowledge is positive, and more than often based on normative models of social and political reality. Yet, what makes political psychology distinctive is that it deals with what Hannah Arendt has called the 'realm of human affairs' (Arendt, 1958). Politics (and political behaviour) is not a dimension outside this realm of human affairs; it is only, sometimes, mistakenly treated as such. Some political psychologists treat political behaviour as a substantive entity (that can be measured and aggregated, and whose distribution can be accounted for in statistical form); others have treated it as a concept or idea, a sensitising concept that guides rather than prescribes the steps taken by their enquiries, anything other than fixed, stable, inevitable or 'real'. 
Cambridge University Press

978-1-107-01768-9 - Political Psychology: Critical Perspectives

Cristian Tileagă

Excerpt

More information

There would be no talk of public opinion, values, prejudice, collective memory, political rhetoric, social and collective identities, and so on outside the social practices of people and outside 'the psychological social contract' witnessed in the 'collaboratively constructed and collectively upheld versions of social reality that come to dominate society' (Moghaddam, 2008, p. 882). Political psychologists tend to restrict themselves to describing what the social and political world means to them, neglecting, in the process, what it means to the social actors that participate in and create that world.

\section{Overview of the book}

The field of political psychology is a continually expanding one. The book offers a selective, yet coherent, presentation of a diverse field. Inevitably, only a segment of relevant literature has been included.

Each of the chapters of this book argues that political behaviour must be looked at as an issue in its own right. This includes exploring the idea that political behaviour should be treated more as an evolving and transforming field of social activities and social practices, charting its symbolic, communicative, social interactive manifestations, made and unmade in social relations between people. Chapters also discuss the value of analysing the range of social judgements, political commitments and positions, issues of stake and accountability, made relevant by social and political actors in talk or texts. Political meanings and communications are 'far more volatile than is commonly supposed' (Edelman, 2001, p. 82). Increasingly, it is the subjective, contingent meanings that people attach to political behaviour that can predict or determine its political consequences.

The first two chapters of this book focus on public opinion and human values against the background of understanding social change and democratisation processes. The first chapter focuses on public opinion, dilemmas of ideology and the rhetorical complexity of attitudes in the context of researching nostalgia for communism and appreciating the democratic competence of individuals. Chapter 2 focuses on universalistic and aggregate models of human values and extends the argument from the first chapter to the democratic competence of nations and the spreading of democratic values. The two chapters urge political psychologists to resist the temptation to purge political behaviour of dilemmas, ambiguities and apparent contradictions.

Chapter 3 proposes a discussion of the political psychology of intolerance by suggesting an alternative conception of prejudice as social accomplishment and discursive study of delegitimisation and dehumanisation 
Cambridge University Press

978-1-107-01768-9 - Political Psychology: Critical Perspectives

Cristian Tileagă

Excerpt

More information

of ethnic minority groups. Chapter 4 introduces the reader to the study of social representations as building blocks of understanding community life and meaning-making. The chapter asserts that social and political reality 'has no smooth and direct passage to knowledge' (Jovchelovitch, 2007 , p. 99); rather, it is mediated by social representations as cultural resources and foundations of 'thinking' societies.

Chapter 5 contends that the key task of political psychology is to analyse the social nature of identities and group practices. It argues that identities are not merely activated but rather elicited and moulded by the social context in which they become relevant. The chapter constructs an argument against the commonly held idea that 'singular identities [can] reliably predict behaviour, attitudes and values' (Wetherell, 2009 b, p. 10). Chapter 6 discusses the issue of collective memory and its link to and influence on political narratives. It proposes a sociocultural approach to researching collective memory that can help political psychologists to turn it into a proper object of political psychological concern. The chapter argues that political psychologists need to study memory as a social and cultural product, and remembering/forgetting as social and cultural practices.

Chapter 7 extends the notion of political behaviour to the pragmatics of discourse and communication, and the mutual relationship between discourse and politics. The chapter argues that discursive actions are socially constitutive of social conditions, social and political 'realities' and discursive practices of various kinds reproduce visions of people, society and politics. Chapter 8 continues the discussion in Chapter 7 by arguing that political discourse needs to be studied as a social activity. Both chapters argue that the key aim of political psychology is to further the systematic study of politics in action, the study of people's practices and social interaction. Both chapters argue for a reorientation of political psychology to researching how politics is done in everyday and elite language practices, and identifying the 'rhetorical conditions' under which politics is actually performed. Social and political 'reality' or 'context' cannot be said to exist without social interactions and communications between people.

Chapter 9 introduces a discursive approach to political communication and mass-mediated politics. The chapter argues that political communications should be considered as carefully produced discourse, an interactive and social interactional process of political meaning making. A focus on language and communication processes can give political psychologists a more comprehensive foundation from which to address the complexity and the continually transforming nature of political communications. The chapter shows how political psychologists can learn 
Cambridge University Press

978-1-107-01768-9 - Political Psychology: Critical Perspectives

Cristian Tileagă

Excerpt

More information

from conceptions of political behaviour in media, communication and discourse studies.

The Epilogue argues that political psychology can only move profitably forward if it does not continue to ignore its past and its rich heritage from around the world. The field of political psychology has the potential to contribute to understanding and tackling social problems in the real world. Fulfilling its potential will require not only devising state-of-theart methodological innovations or insisting on theoretical borrowings from neighbouring disciplines of psychology. It will require, primarily, extending its (many) definition(s) of political behaviour to include language, culture, social representations, communication and alternative approaches which are no less 'scientific' than the experimental or survey canon. It will require reconsidering the image of the person implicit in contemporary scientific approaches and theoretical imports. It will require re-examining its conception of the relation between individual psychology ('human nature') and collective performances ('culture'). Only by exploring, developing and pursuing systematically an interpretive outlook, can political psychology become a genuine social and political anthropology of modern culture. 
Cambridge University Press

978-1-107-01768-9 - Political Psychology: Critical Perspectives

Cristian Tileagă

Excerpt

More information

\section{Public opinion and the rhetorical complexity} of attitudes

\section{The collective will and the 'ideal' democratic citizen}

'We, the people, feel and know that we have become more significant than ever before, with the narrowing of the barrier that separates "us" and our range of experiences from our elected representatives and their range of experiences.' This is what social psychologist, Hadley Cantril, in his 1942 paper, 'Public Opinion in Flux', was writing about the importance of 'good morale' in American democracy, especially 'national morale' associated with the war effort. What Cantril acknowledged in 1942 (and he was not the only one) is what politicians, 'spin doctors', and so on take for granted today: the fundament of democracy lies in the 'faith in the judgment of the common man'. Cantril was writing about the person, the 'citizen' who 'given sufficient facts and motivated to pay attention to those facts ... will reach a decision based on his [her] own self-interest as a member of a democratic community' (1942, p. 151). When writing about 'we, the people' Cantril points to the direction of political democratic accountability (from citizens to their elected representatives) and thus brings into the foreground one of the most fundamental political hopes - that the will and reason of 'the people' ought to prevail. Cantril's words express faith in the selfgoverning, autonomous and omnicompetent citizen (Dalton, 2008) the 'ideal' democratic citizen.

This chapter shows how political psychologists' concern with the 'collective will' is paralleled by a concern with, search for and description of the democratic citizen. The first part of the chapter maps the various meanings and expressions of this collective will condensed into the notion of 'public opinion'. The chapter then goes on to describe the main assumptions behind researching and understanding the democratic competence of citizens, especially those related to political knowledge and political sophistication.

The remainder of the chapter is dedicated to exploring the idea that public opinion is one of most debated expressions of democratic 
Cambridge University Press

978-1-107-01768-9 - Political Psychology: Critical Perspectives

Cristian Tileagă

Excerpt

More information

politics. It focuses on the rhetorical complexity of attitudes and paradoxes of opinion that arise in the course of attempts to reconcile with the communist past in Eastern Europe. In doing so, it challenges the notion that people carry in their heads fully formed or preformed attitudes. The chapter argues that it is important to show how social actors are appraising social/political realities and how attitudes and political experiences possess a highly visible rhetorical complexity. These concerns are developed further in later chapters of this book, especially Chapter 6 (with reference to collective memory and political narratives), Chapter 7 (with reference to the role of language in politics) and Chapter 8 (with reference to the complexity of political rhetoric). The chapter ends by arguing that political psychology scholarship should be more about what citizens themselves expect of democracy and perhaps less about what democracy expects of citizens.

The ideological cleavages of societies create their own models, images of 'ideal' democratic citizens - what Lakoff (2002) has called 'model citizens'. In the United States, for instance, national politics engenders its own categories of moral politics and moral action (the 'ideal' conservative citizen is diametrically opposed to the 'ideal' liberal citizen). ${ }^{1}$ Political psychology offers the best examples of a search for the 'ideal' democratic citizen, where the stability of preferences and world views (Ansolabehere et al., 2008; Converse, 1964) goes together with the belief that democratic experience can be maximised by accommodating individual differences (Mondak and Hibbing, 2012; Stenner, 2005). In their search for the 'ideal' democratic citizen, political psychologists build and rely on 'convenient fictions' (Riesman, 1954), and they build models of social and political behaviour that emphasise rationality over irrationality, responsibility over irresponsibility, citizenship over other means and ways of belonging and acting in society. It has been argued that this search for and description of the collective will and 'ideal' democratic citizen is one of the foundational 'mystical fallacies of democracy', an unattainable, 'false ideal' (Lippmann, [1927] 2009).

\section{Political knowledge and the democratic competence of citizens}

The study of democratic competence of citizens and involvement in politics starts with the classic observation that the ordinary citizen fails to

\footnotetext{
${ }^{1}$ As Lakoff argues 'conservative and liberal categories for moral action create for each moral system a notion of a model citizen - an ideal prototype - a citizen who best exemplifies forms of moral action' (2002, p. 169).
} 